\title{
Chemistry and Nature
}

\author{
Benjamín Ruiz Loyola* \\ Faculty of Chemistry, Unam \\ *Corresponding author: Benjamín Ruiz Loyola, Faculty of Chemistry, Unam
}

\begin{tabular}{lll}
\hline ARTICLE INFO & & ABSTRACT \\
\cline { 1 - 1 } $\begin{array}{ll}\text { Received: } \\
\text { Published: December 18, } 2019\end{array}$ & & $\begin{array}{l}\text { Citation: Benjamín Ruiz Loyola. Chemistry and Nature. Biomed J Sci \& Tech Res 24(1)- } \\
\text { 2020. BJSTR. MS.ID.003995. }\end{array}$ \\
\hline
\end{tabular}

\section{Opinion}

The herbal tradition of ancient peoples has for years been the basis of our pharmacy and our medicine. Drinks prepared with herbs or roots have given us, directly or indirectly, remedies and medications. Thus, the use of clove as an analgesic in dental problems, of Jamaica as a diuretic or for bronchitis or of aloe vera for burns and ulcers, is something closely linked to the empirical knowledge of our ancestors. The use of plants has led science to separate from them the substance that has activity as a medicine, what we call active ingredient, and in many cases to improve it. The most publicized and notorious case is that of the best known and consumed analgesic in the world: acetylsalicylic acid, better known as Aspirin. White willow has historically been used as an analgesic, anti-inflammatory and antipyretic (reduces fever), since the time of Hippocrates, in the fifth century before our era. In the active ingredient of the white willow tree was isolated, which later turned out to be salicylic acid.

If this acid was administered directly, its effects were excellent, but it had (has) the disadvantage that it is too irritating to the walls of the stomach, so it was sought to modify its chemical structure to make it more consumer friendly. Thus, it was until 1897 that Felix Hoffman synthesized and tested acetylsalicylic acid when working for Bayer laboratories. At present, it is one of the best-selling drugs worldwide; It is estimated that daily consumption is close to one hundred million tablets. And not only is it used as an analgesic, anti-inflammatory and antipyretic, it is also used to prevent heart attacks and as an anticoagulant. On the other hand, the most potent anesthetic and analgesic, morphine, is obtained directly from the poppy; unfortunately, unscrupulous people transform morphine into heroin, which causes addiction (morphine also causes it, but is always used under strict medical supervision). One of the most used medications in the case of breast cancer is taxol, which was initially obtained from a tree, a variety of yew called Taxus Brevifolia.
Currently it is also used against lung and ovarian cancer. This is only a sample of the use of a plant as a medicine and the transformation of the active substance of that plant into a better product. Science (mainly chemistry) joins nature to provide us with a better quality of life, but it no longer only focuses on the use of natural raw materials of terrestrial plant origin; we have begun to turn to what can be a more abundant and extensive source of raw materials of all: the sea. For natural reasons, the sea and marine organisms (fish, mollusks, plants, algae, etc.) have been poorly studied from the point of view of chemistry, but as technology has been available to explore and obtain sufficient specimens For lab work, we have found truly amazing things. The first one is somewhat obvious: humans have the seas turned into true garbage dumps where we find the same waste of corroded metals, plastic and mechanical parts (including whole ships) that remains of fuels and lubricants, oil or chemical weapons abandoned. However, this is not the central theme this time. Today we will talk a little about what the sea gives us in terms of raw materials for the preparation of medicines that protect our health or help us recover it, if it has deteriorated.

\section{Here we will talk of a Few Examples}

Many seaweeds are a source of different compounds that have a high antimicrobial activity (which fights microbes). For example, the algae Corallina officinalis and Cystoseira barbata, among others, have activity to combat microorganisms such as some staphylococci (the best known is $S$. Aureus, associated with pneumonia, skin infections and food poisoning) and some escherichias ( for example, Escherichia coli and Escherichia fecalis, which cause diarrhea on very severe occasions and with bleeding). In this way, there are novel medicines to combat these microorganisms, beyond traditional antibiotics, to which resistance has been developed by the microbes 
that cause these diseases. In this line of work, to defeat antibioticresistant microorganisms, it has been found that dictyota acutiloba algae has good activity against methicillin-resistant $S$. aureus, for example.

Our terrifying neighbors, sharks, are possessed in their tissues of a cholesterol-like compound, called squalamin, that fights viruses (for example, dengue, hepatitis B and D and is said to have cancer potential. Better news is that the total synthesis of squalemine has been known since the mid-990s, so it is not necessary to attack sharks to dispose of the active compound. A recent study conducted in India, accounts for 7 different types of seaweed, with some type of antimicrobial activity, which open doors to more research and a new era in the fight against microorganisms that harm our body and put at risk to our health. And not only can we find raw materials in the algae, it happens that there are also marine bacteria that can be a source for various materials of medical importance. For example, a gram-positive bacterium found in a deep-sea sediment produces a series of novel natural products, the so-called A-F macrolactin, a linear acetogen of 24 carbon atoms, which have various types of activity.

The main product, macrolactin A, in vitro studies inhibits murine melanoma B16-F10 cells, shows the inhibition of the herpes simplex virus and protects T lymphocytes against HIV virus replication. On the other hand, a metabolite of a microorganism (from Alteromonas spp.) with a good anti-HIV potential has been isolated from the Bermudian sponge tissue. Some bacteria of the Vibrio genus produce a series of extracellular proteases; For example, Vibrio alginolyticus produces six proteases, including an alkaline serine exoprotease, unusually resistant to detergents. A marine fungus (Scopoluriopsis brevicaulis) produces a couple of substances with anticancer activity, called Scopularide A and B. And like these, there are already hundreds, if not thousands of examples, to which we should add what has not been discovered. Anyway, it's a fact that the vast empire of the sea promises to employ dozens of chemists in the future, so if we come from the sea and left it to live on the planet's surface, we must return to it to live healthier. Life takes many turns [1-4].

\section{References}

1. Rajeev Kamar Jha, Xu Zi Rong (2004) Marine Drugs 2: 123-146.

2. Kramer A, Paun L, Imhoff JF, Kempken F, Labes A (2014) Development and validation of a fast and optimized screening method for enhanced production of secondary metabolites using the marine Scopulariopsis brevicaulis strain LF580 producing anti-cancer active Scopularide A and B. PLOS one 9(7): e103320.

3. Livett BG, Gayler KR, Khalil Z (2004) Drugs from the sea: Conopeptides as potential therapeutics, Current Medicinal Chemistry 11: 1715-1723.

4. Indap MM (2009) Drugs from the sea. Indian Journal of Marine Sciences 38(1): 7-9.

\section{ISSN: 2574-1241}

DOI: $10.26717 /$ BJSTR.2020.24.003995

Benjamín Ruiz Loyola. Biomed J Sci \& Tech Res

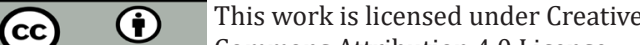

Submission Link: https://biomedres.us/submit-manuscript.php

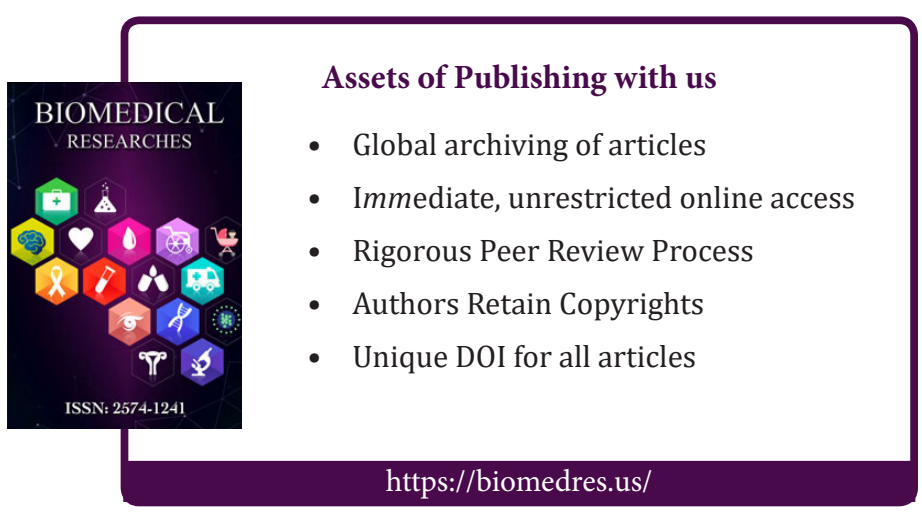

